another finger, the attention of the ear is fixed on the pitch of this partial. The damping finger is then removed, and the string is plucked sharply at a point not far from the end to elicit the full series of partials. The observer listens carefully for the 5 th partial for a second or so, and then touches the string exactly at its node so as to damp out all the partials lower than the $5^{\text {th. }}$. The $5^{\text {th }}$ partial then sings out, and though theoretically its intensity should have been the same, actually a large apparent increase of intensity is usually perceived. The sound of the $5^{\text {th }}$ partial, previously masked by the sound of the graver partials, asserts itself with vehemence when they are removed.

A further confirmation of these ideas is furnished by studies of the manner in which the audibility of the upper partials alters when the absolute intensity of the sound or its quality is varied. These details are reserved for consideration in a forthcoming paper.

2 Io Bowbazaar Street, C. V. RAMAN.

Calcutta, India, January 27.

\section{Intensification of the Metallic Image in Gerlach and Stern's Magnetic Experiments.}

In the course of some attempts to measure the magnetic moment of the cadmium atom by a slight modification of Gerlach and Stern's original arrangement, a new method of intensifying the effect of a deposit of a very small number of metallic atoms on glass has been used, which although perhaps rather obvious has not, so far as I can ascertain, been employed for this purpose before. In Gerlach and Stern's first experiments on the silver atom a chemical method of rendering the deposit of atoms on the glass plate visible was used. In their later experiments on other metals it was found that in certain cases the deposit was visible without intensification, but in others it had to be developed by the same means. It is, however, plain that the use of comparatively huge quantities of liquid when dealing with a metallic deposit which may be at the most on the average only one molecule thick is dangerous, as solution of the deposit might easily occur. The method now to be described avoids this difficulty and is also probably easier to work. It depends on the fact that, while cadmium vapour at low pressures will not condense on a clean glass surface at ordinary temperatures, it does so readily at liquid air temperature. If, however, the smallest deposit of cadmium is already present on the glass, the vapour will condense on it at ordinary air temperature, quickly forming a visible deposit.

This phenomenon was originally discovered by Langmuir. He showed that by its use it was possible to obtain a visible deposit if only one cadmium atom per 3000 surface molecules of the glass was present. It is accordingly eminently suitable for our purpose. During the course of an experiment, the bottom of the glass flask on which the cadmium atoms impinge after passing through the magnetic field is immersed in liquid air. At the end of the experiment, to intensify the cadmium image, it is only necessary to remove the liquid air, allow the glass vessel to attain air temperature, and then evaporate a small quantity of cadmium inside the vessel by suitable means. The cadmium vapour will now only condense on the glass surface which has already a small trace of cadmium on it, and it has been found that a visible deposit quickly forms if any such trace is present. Blank experiments have also shown that if there is no cadmium originally present on the glass, no deposit will form. The pressure of the developing cadmium vapour must not be raised too high, as if this is done it may in certain circumstances condense on clean glass. In practice, however, it fortunately does not seem very easy to attain this state, especially if any metal objects are present in the vacuum, as the cadmium will readily condense on them, thus quickly lowering the pressure.

This method of intensifying small metallic deposits on glass can also be used in the cases of the other more volatile metals such as zinc and magnesium. It is also perhaps indirectly applicable to metals such as copper, which condense on glass at air temperature, as my experiments seem to show that cadmium vapour will condense on most metals at air temperature. Whether, however, a very few atoms of another metal will cause the cadmium vapour to condense I have not yet succeeded in proving, but on the whole the outlook seems hopeful. It is also possible that the presence of an electric charge on the surface of a quartz plate might cause condensation, but again this point has not been tried. However, without entering on these possible applications, it is evident that this method may be of great use in any experiments in which we have to deal with streams of either atoms or molecules the velocity of which is too low to affect a photographic plate, and the presence of which it is accordingly very hard to detect.

Physical Laboratory,

$$
\text { J. H. J. POOLE. }
$$

Trinity College, Dublin

$$
\text { February } 20 .
$$

\section{Greenland or Polar Front ?}

No meteorologist could be less disposed than myself to underrate the importance of Greenland as a factor in determining the characteristic circulation over the North Atlantic Ocean, but I challenge the extravagant contention that cyclonic circulation, which is an integral part of the general circulation, depends entively upon the "katabatic" operations of a relatively small and accidental feature in the configuration of the northern hemisphere like Greenland. To contend that the analogous Pacific centre of cyclonic activity, scarcely less intense than the Atlantic, is nourished by the same katabatic action of Greenland's ice-dome is surely out of the question.

Owing to pressure on space I cannot deal in any detail with the points raised in Prof. Hobb's letter to NATURE of February I3, but will briefly indicate the general line of reply. First of all, the discrepancy between the fact of relatively high pressure over the North Pole and the fact that the Fram, in the course of her drift in 1895 along the 85 th parallel in the European sector of the Arctic, experienced a slight, Io per cent, excess of southerly over northerly winds, can be reconciled by a closer study of Mohn's isobaric charts, which show a shallow elongation of the Icelandic pressure minimum north-eastwards towards Spitsbergen. With the trend of the isobars in this particular sector the slight excess of southerly winds recognised by Mohn himself is quite consistent. But the major fact of the existence at all seasons of an "Arctic Wind Divide," shown by Mohn to lie across the polar basin between the Atlantic and Pacific minima, means that in the day-to-day changes there must be many occasions when air drains southwards over Europe whether reinforced from Greenland or not; and I am sure that any British weather forecaster will bear me out that there are many such occasions.

Secondly, the monthly distribution of the fogfrequency shows that only June, July, August, and September during the voyage of the Fram could in

NO. 2943, VOL. II 7 